\title{
Article \\ Population Parameters and Growth of Riptortus pedestris (Fabricius) (Hemiptera: Alydidae) under Fluctuating Temperature
}

\author{
Jeong Joon Ahn * and Kyung San Choi
}

check for

updates

Citation: Ahn, J.J.; Choi, K.S. Population Parameters and Growth of Riptortus pedestris (Fabricius) (Hemiptera: Alydidae) under Fluctuating Temperature. Insects 2022, 13, 113. https://doi.org/10.3390/ insects13020113

Academic Editor: Victor Benno Meyer-Rochow

Received: 18 December 2021

Accepted: 17 January 2022

Published: 21 January 2022

Publisher's Note: MDPI stays neutral with regard to jurisdictional claims in published maps and institutional affiliations.

Copyright: (C) 2022 by the authors. Licensee MDPI, Basel, Switzerland. This article is an open access article distributed under the terms and conditions of the Creative Commons Attribution (CC BY) license (https:// creativecommons.org/licenses/by/ $4.0 /)$
Research Institute of Climate Change and Agriculture, National Institute of Horticultural and Herbal Science, RDA, 1285 Aejo-roo, Jeju-do, Jeju-si 63240, Korea; mutant8@korea.kr

* Correspondence: j2ahn33@korea.kr; Tel.: +82-64-741-2582

Simple Summary: The bean bug, Riptortus pedestris, is a polyphagous species that is an important pest of soybean fields in Asian countries. In this study, we examined the effects of constant and fluctuating temperatures on the development and reproduction of $R$. pedestris. The effects of thermal conditions were assessed by constructing age-stage, two-sex life tables from a constant temperature of $24^{\circ} \mathrm{C}$ and simulated fluctuating temperatures of $24 \pm 4^{\circ} \mathrm{C}, 24 \pm 6^{\circ} \mathrm{C}$, and $24 \pm 8^{\circ} \mathrm{C}$. At a constant temperature, a number of $R$. pedestris life table parameters differed from those under fluctuating temperatures. Although similar pre-adult development periods were recorded under constant and fluctuating temperatures, the periods of female longevity and oviposition periods under fluctuating temperatures were significantly longer than those at a constant temperature. Given that temperature is an important abiotic factor for forecasting the population dynamics of arthropods in nature, determining the effects of fluctuating temperatures will make a valuable contribution to predicting R. pedestris population growth.

Abstract: In this study, we determined the influence of fluctuating temperatures on the development and fecundity of the bean bug Riptortus pedestris (Fabricius) (Hemiptera: Alydidae) by collecting life table data for individuals exposed at a constant temperature $\left(24^{\circ} \mathrm{C}\right)$ and three fluctuating temperatures $\left(24 \pm 4{ }^{\circ} \mathrm{C}, 24 \pm 6{ }^{\circ} \mathrm{C}\right.$, and $24 \pm 8{ }^{\circ} \mathrm{C}$ ). The raw life history data were analyzed using an age-stage, two-sex life table to take into account the viable development rate among individuals. Based on these analyses, the population projections enabled us to determine the stage structure and variability of population growth under different temperature treatments. Our results revealed shorter periods of immature development and a higher pre-adult survival rate at $24 \pm 6{ }^{\circ} \mathrm{C}$ than under the other assessed temperature conditions. Furthermore, significant reductions in female longevity were recorded at $24^{\circ} \mathrm{C}$, whereas the fecundity, net reproductive rate, and intrinsic and finite rates of increase were highest at $24 \pm 6{ }^{\circ} \mathrm{C}$. These findings reveal that fluctuating temperatures have a positive influence on the life history traits of $R$. pedestris and indicate that observations made under constant temperatures may not explain sufficiently enough the temperature dependent biological performances of pests in the field.

Keywords: Riptortus pedestris; life table; population projection; temperature

\section{Introduction}

The bean bug Riptortus pedestris (Fabricius) (Hemiptera: Alydidae) is an important pest of soybean fields in Asian countries, including China, India, Japan, and South Korea [1-5], and is the major insect pest responsible for staygreen syndrome in Chinese soybean [5]. $R$. pedestris attack the soybean pod and seeds by piercing and sucking, and the damage thus inflicted can result in substantial economic losses.

Climate change has attracted worldwide attention, and it is becoming important to understand the influence of the incidence and severity of climate on insect pests in agriculture [6-8]. Temperature is a notable abiotic factor that facilitates the behaviors, 
biochemical reactions, development, fecundity, and physiology of the insects and influences population dynamics and the structure and functioning of ecosystems [9-15]. Insects exposed to ambient temperatures above and below daily mean temperatures follow a thermal cycle. Thermal performance curves of insects show an asymmetric nature meaning the warming phase of a cycle has a more beneficial impact on the ecological and physiological responses of insects than the cooling phase [11,16,17]. Knowledge of the adaptations of insects to different climatic conditions can make an important contribution to predicting the emergence of pests.

Life table analysis can yield two types of information, namely, the essential results and derived parameters, and provides a comprehensive understanding of the life history of a population cohort. Currently the age-stage, or the two-sex life table theory, is widely used as it incorporates both sexes and accounts for variable developmental rates among individuals, as well as reveals the stage differentiation of individuals in a given population [18-25]. Numerous published studies have reported on the effects of constant temperatures on the demographic characteristics and population parameters of R. pedestris $[10,26,27]$. Kim et al. [26] investigated the temperature-dependent development and survival at seven constant temperatures and examined the longevity and reproduction of $R$. pedestris at six different constant temperatures. Although they did not show the life table parameters of $R$. pedestris, the mean total fecundity was highest at $25^{\circ} \mathrm{C}$. Ahn et al. [10] conducted an experiment on temperature-dependent development at eleven constant temperatures and for adult longevity and oviposition at six constant temperatures. Ahn et al. [10] showed that the net reproductive rate (RO) of $R$. pedestris was highest at $24^{\circ} \mathrm{C}$, although the intrinsic rate of increase was highest at $32.6^{\circ} \mathrm{C}$ using methods proposed by Maia et al. [28]. However, to the best of our knowledge, there have been no studies to date that have examined the effects of fluctuating temperature conditions on the lifecycle of $R$. pedestris. Fluctuating temperatures lead to ecological, life history, and physiological consequences for insects that diverge from those predicted from constant temperatures. Fluctuating temperatures that remain within permissive temperature ranges improve biological performance [11,29-35]. This study hypothesized that fluctuating temperatures remaining within the permissive thermal range influence the life history parameters of $R$. pedestris. We accordingly collected detailed life history data on the development, survival, reproduction, and longevity rates of $R$. pedestris under a single constant and three fluctuating temperatures to determine the population parameters and predict the population growth of $R$. pedestris populations. Specifically, we analysed the raw life history data using age-stage, two-sex life tables and then used the data thus obtained to project population growth under different temperature conditions.

\section{Materials and Methods}

\subsection{Insect Maintenance}

A colony of $R$. pedestris was obtained from the National Institute of Agricultural Sciences (NIAS), Wanju-gun, Korea. Colonies of the bug were maintained in acrylic cages $(30 \mathrm{~cm} \times 30 \mathrm{~cm} \times 35 \mathrm{~cm})$ comprising of two meshed screens on the lateral sides for ventilation and a sliding door. The cages were maintained at $25 \pm 1{ }^{\circ} \mathrm{C}$ and $60 \% \pm 10 \%$ relative humidity under a $16 \mathrm{~h}: 8 \mathrm{~h}$ light:dark photoperiod. Soybean seeds (var. Baegtae) and water were supplied as a food source. Three pieces of gauze $(10 \mathrm{~cm} \times 4.5 \mathrm{~cm})$ were placed at the bottom of each cage as oviposition substrates. To prevent inbreeding depressions, field-collected $R$. pedestris from Jeju were added to cages for mass rearing.

\subsection{Laboratory Experiment}

Freshly deposited $R$. pedestris eggs ( $<24 \mathrm{~h}$ old) were randomly selected from the insect-rearing system and placed in Petri dishes $(10.0 \mathrm{~cm}$ diameter and $4.0 \mathrm{~cm}$ height; SPL, Pocheon, Korea), the lids of which contained a $4.0 \mathrm{~cm}$ diameter air hole covered with a $0.05 \mathrm{~mm}$ mesh. Water-soaked cotton was placed in each dish to maintain humidity and the dishes were transferred to a controlled temperature chamber. After eclosion, the first-instar 
nymphs were selected with a brush and placed individually in Petri dishes $(5.0 \mathrm{~cm}$ diameter and $1.5 \mathrm{~cm}$ height with a $1.3 \mathrm{~cm}$-diameter air hole in the lid covered with $0.05 \mathrm{~mm} \mathrm{mesh}$ ). Each dish was initially lined with water-soaked cotton, and three dried soybean seeds were placed in the Petri dishes and prevented from rolling with a plastic band. Soybean seeds and water were supplied as a food source for the nymphs.

Nymphal development and survival were observed at daily intervals, with the presence of an exuvium used as evidence of molting to the next developmental stage. Sample sizes were greater than 100 eggs per treatment. The nymphs were allowed to complete development to the adult stage within the Petri dishes, with developmental time for each life stage being recorded. The dried soybean seeds were replenished whenever necessary. After the emergence of adults, male and female bugs were paired and transferred to new Petri dishes $(10.0 \mathrm{~cm}$ diameter and $4.0 \mathrm{~cm}$ height) for oviposition, with rolled pieces of gauze $(10 \mathrm{~cm} \times 4.5 \mathrm{~cm})$ lining the base of the dishes and serving as oviposition substrates. For each temperature treatment, the reproductive period, fecundity, survival, and longevity of the bugs were recorded for each individual environment until the deaths of all adults. In cases when one member of the paired bugs died earlier than its mate, the surviving individual was paired with an adult of the opposite sex derived from the colonies of massreared $R$. pedestris. Eggs laid by the female were removed from the containers to assess the daily fecundity and hatchability. Insects were also maintained separately in each of the controlled temperature chambers for the entire life table study period.

The developmental periods of $R$. pedestris stages from egg-to-adult emergence were assessed at temperatures of $24.0{ }^{\circ} \mathrm{C}, 24 \pm 4{ }^{\circ} \mathrm{C}, 24 \pm 6{ }^{\circ} \mathrm{C}$, and $24 \pm 8{ }^{\circ} \mathrm{C}$ as well as a relative humidity within the range of $65-80 \%$. These environmental data were recorded at 1-h intervals using a HOBO data logger (Onset Computer, Co., Bourne, MA, USA). The growth chamber under constant temperature regimes held the target temperature constant $\left( \pm 0.3^{\circ} \mathrm{C}\right)$ for the entirety of the study. Rate of temperature increase or decrease varied depending on temperature treatment (Supplementary Figure S1). For fluctuating temperature regimes, growth chambers were programmed with incremental temperature increases hourly depending on fluctuating temperature regimes; $24 \pm 4{ }^{\circ} \mathrm{C}$ was $0.4{ }^{\circ} \mathrm{C}$, $24 \pm 6{ }^{\circ} \mathrm{C}$ was $0.8^{\circ} \mathrm{C}$, and $24 \pm 8{ }^{\circ} \mathrm{C}$ was $2{ }^{\circ} \mathrm{C}$, respectively. The incremental decrease in temperature was $1^{\circ} \mathrm{C}$ at 1 -h intervals under each fluctuating temperature treatment. The temperature and relative humidity within the chambers were checked per week for maintaining experimental conditions. The temperatures recorded within the cages were established to be very similar to those of the chambers (WTH-305, Daihan Scientific, Co. Ltd., Seoul, Korea) in which they were maintained.

\subsection{Life Table Data Analysis}

The life history data of $R$. pedestris, namely their developmental duration, survival, longevity, fecundity, life expectancy, and population parameters, were analyzed by implementing the age-stage, two-sex life table theory [36] and the method described by Chi [37] using the computer program TWOSEX-MSChart [38]. The age-stage-specific survival rate $\left(s_{x j}\right.$, where $x=$ age and $j=$ stage), age-specific survival rate $\left(l_{x}\right)$, age-stage-specific fecundity $\left(f_{x j}\right)$, and age-specific fecundity $\left(m_{x}\right)$, as well as the population parameters including net reproductive rate $\left(R_{\mathrm{o}}\right)$, intrinsic rate of increase $(r)$, finite rate of increase $(\lambda)$, and mean generation time $(T)$ were calculated according to Chi and Liu [36] using the following equations:

$$
\begin{gathered}
l_{x}=\sum_{j=1}^{k} S_{x j} \\
m_{x}=\frac{\sum_{j=1}^{k} S_{x j} f_{x j}}{\sum_{j=1}^{k} S_{x j}} \\
R_{O}=\sum_{x=0}^{\infty} l_{x} m_{x}
\end{gathered}
$$




$$
\begin{gathered}
\sum_{x=0}^{\infty} e^{-r(x+1)} l_{x} m_{x}=1 \\
\lambda=e^{r} \\
\mathrm{~T}=\frac{\ln R_{O}}{r}
\end{gathered}
$$

where $k$ is the number of stages. The survival rate $\left(s_{x j}\right)$ is defined as the probability that a newly laid egg will survive to age $x$ and stage $j$, and fecundity $\left(f_{x j}\right)$ is the number of hatched eggs produced by a female adult at age $x$. Age-specific fecundity $\left(m_{x}\right)$ is calculated to take into account individuals of different stages at age $x$. The net reproductive rate $\left(R_{\mathrm{o}}\right)$ is defined as the total number of offspring that an individual can produce during its lifetime, whereas the intrinsic rate of increase $(r)$ is calculated using the Euler-Lotka formula with age indexed from day " 0 " [39]. The mean generation time $(T)$ represents the period that a population requires to undergo an $R_{0}$-fold increase of its original size as time approaches infinity and the population growth rate settles down to the intrinsic rate of increase. Owing to the variable development rates in many insect populations, the overlapping of stages in their life history is examined where individuals of the same age have different developmental stages [6]. The age-stage-specific life expectancy $\left(e_{x j}\right)$, which is the length of time an individual of age $x$ and stage $j$ is expected to live, was calculated as follows:

$$
e_{x j}=\sum_{i=x}^{\infty} \sum_{y=j}^{k} s s_{i y}
$$

where $e_{x j}$ is the probability that an individual of age $x$ and stage $j$ will survive to age $i$ and stage $y$, which is calculated by assuming $s s_{i y}=1$.

The age-stage reproductive value $\left(v_{x j}\right)$ is the contribution of an individual of age $x$ and stage $j$ to the future population, and is calculated as follows [40]:

$$
v_{x j}=\frac{e^{r(x+1)}}{s_{x j}} \sum_{i=x}^{\infty} e^{-r(i+1)} \sum_{y=j}^{k} s_{i y} f_{i y}
$$

The adult pre-oviposition period (APOP) is defined as the pre-oviposition period based on adult female age, whereas the total pre-oviposition period (TPOP) takes into consideration the total time from birth to the initial oviposition. The standard errors of development time, longevity, fecundity, and population parameters were calculated using the bootstrap method with 100,000 bootstrap replicates. Differences among the different treatments were analyzed using a paired bootstrap test of the TWOSEX-MSChart program at the $5 \%$ significance level $[20,41]$.

\subsection{Population Projection}

To predict and compare the population growth and age-stage structure of R. pedestris reared under constant and fluctuating temperatures, we used life table data for the developmental periods, survival rate, and fecundity to simulate population growth in the TIMING-MSChart program [42]. For comparative purposes, the same initial population of 10 newly laid eggs was used for the simulation of each treatment. The data file for TIMING-MSChart was created using TWOSEX-MSChart to reduce the complex process of preparing data files for TIMING-MSChart. We projected the increase rate of stage $j$ from time $t$ to $t+1$ using the common logarithm, as the stage differentiation during population growth is described by the TWOSEX-MSChart analysis. We calculated the rate of increase of stage $j$ from time $t$ to $t+1$ by using a natural logarithm [8]:

$$
\varphi_{j, t}=\ln \left(\frac{n_{j, t+1}+1}{n_{j, t}+1}\right)=\ln \left(n_{j, t+1}+1\right)-\ln \left(n_{j, t}+1\right)
$$


Given that it is not possible to use logarithmic transformation when the number of individuals at a certain stage is $0\left(n_{j, t}=0\right.$ or $\left.n_{j, t+1}=0\right)$, we used $n_{j, t}+1$ and $n_{j, t+1}+1$ in the calculation process.

\section{Results}

Parameters related to the development of each life stage and the reproduction of the adult females under the four different controlled temperature conditions are summarized in Table 1. The pre-adult duration ranged from $34.0 \mathrm{~d}$ at $24 \pm 6{ }^{\circ} \mathrm{C}$ to $41.4 \mathrm{~d}$ at $24 \pm 4{ }^{\circ} \mathrm{C}$, whereas the longevity and oviposition periods of the adult females increased with increasing temperature fluctuation until $24 \pm 6{ }^{\circ} \mathrm{C}$. The shortest reproductive period (35.4 d) and the APOP (5.3 d) were observed at $24^{\circ} \mathrm{C}$, and the highest mean fecundity was recorded at $24 \pm 6{ }^{\circ} \mathrm{C}$ (321.1 eggs/female), followed by that at $24{ }^{\circ} \mathrm{C}(221.6 \mathrm{eggs} / \mathrm{female})$, $24 \pm 4{ }^{\circ} \mathrm{C}$ (205.2 eggs/female), and $24 \pm 8{ }^{\circ} \mathrm{C}$ (195.2 eggs/female). The probability that a newly laid egg would survive to the adult stage was $0.83,0.60,0.53$, and 0.52 at $24 \pm 6{ }^{\circ} \mathrm{C}$, $24{ }^{\circ} \mathrm{C}, 24 \pm 8{ }^{\circ} \mathrm{C}$, and $24 \pm 4{ }^{\circ} \mathrm{C}$, respectively, and these values were found to coincide with respective proportions of reproductive adult female individuals $\left(N_{f} / N\right)$ in the cohort (Table 2).

Table 1. Development time, longevity, adult pre-oviposition period (APOP), total pre-oviposition period (TPOP), oviposition days, eggs per oviposition day, and fecundity of all females of Riptortus pedestris under four different temperature conditions.

\begin{tabular}{ccccc}
\hline & \multicolumn{4}{c}{ Temperatures $\left({ }^{\circ} \mathbf{C}\right)$} \\
\cline { 2 - 5 } Parameters & $\mathbf{2 4}$ & $\mathbf{2 4} \pm \mathbf{4}$ & $\mathbf{2 4} \pm \mathbf{6}$ & $\mathbf{2 4} \pm \mathbf{8}$ \\
\hline Egg P & $9.4 \pm 0.04 \mathrm{c}(145)$ & $11.4 \pm 0.08 \mathrm{a}(201)$ & $8.0 \pm 0.05 \mathrm{~d}(208)$ & $10.1 \pm 0.03 \mathrm{~b}(209)$ \\
1st instar P & $3.0 \pm 0.02 \mathrm{~b}(129)$ & $3.2 \pm 0.04 \mathrm{a}(181)$ & $2.9 \pm 0.03 \mathrm{c}(192)$ & $2.4 \pm 0.03 \mathrm{~d}(194)$ \\
2nd instar P & $5.6 \pm 0.09 \mathrm{~b}(119)$ & $6.1 \pm 0.07 \mathrm{a}(136)$ & $5.3 \pm 0.003 \mathrm{c}(187)$ & $4.9 \pm 0.07 \mathrm{~d}(131)$ \\
3rd instar P & $5.0 \pm 0.07 \mathrm{~b}(116)$ & $5.5 \pm 0.09 \mathrm{a}(124)$ & $4.8 \pm 0.05 \mathrm{~b}(187)$ & $5.0 \pm 0.07 \mathrm{~b}(119)$ \\
4th instar P & $5.2 \pm 0.06 \mathrm{c}(110)$ & $6.1 \pm 0.10 \mathrm{a}(110)$ & $5.3 \pm 0.002 \mathrm{bc}(186)$ & $5.5 \pm 0.06 \mathrm{~b}(114)$ \\
5th instar P & $7.1 \pm 0.07 \mathrm{~d}(110)$ & $9.1 \pm 0.20 \mathrm{a}(110)$ & $7.5 \pm 0.04 \mathrm{c}(186)$ & $7.8 \pm 0.06 \mathrm{~b}(114)$ \\
Pre-adult P & $35.4 \pm 0.17 \mathrm{~b}(110)$ & $41.4 \pm 0.35 \mathrm{a}(110)$ & $34.0 \pm 0.13 \mathrm{c}(186)$ & $35.6 \pm 0.18 \mathrm{~b}(114)$ \\
Adult female P & $40.7 \pm 2.74 \mathrm{c}(60)$ & $62.0 \pm 5.76 \mathrm{~b}(54)$ & $91.8 \pm 4.05 \mathrm{a}(110)$ & $78.5 \pm 6.14 \mathrm{a}(59)$ \\
Adult male P & $147.8 \pm 10.50 \mathrm{a}(50)$ & $120.5 \pm 13.26 \mathrm{a}(56)$ & $137.9 \pm 6.62 \mathrm{a}(76)$ & $140.2 \pm 12.42 \mathrm{a}(55)$ \\
APOP & $5.3 \pm 0.11 \mathrm{~b}(56)$ & $9.9 \pm 0.71 \mathrm{a}(54)$ & $5.3 \pm 0.09 \mathrm{~b}(109)$ & $5.7 \pm 0.78 \mathrm{~b}(59)$ \\
TPOP & $40.8 \pm 0.29 \mathrm{~b}(56)$ & $51.1 \pm 0.92 \mathrm{a}(54)$ & $39.5 \pm 0.19 \mathrm{c}(109)$ & $41.2 \pm 0.82 \mathrm{~b}(59)$ \\
Oviposition P & $35.4 \pm 2.24 \mathrm{c}(60)$ & $41.5 \pm 4.42 \mathrm{bc}(54)$ & $69.6 \pm 2.97 \mathrm{a}(110)$ & $44.9 \pm 2.49 \mathrm{~b}(59)$ \\
Fecundity (eggs / female) & $221.6 \pm 15.88 \mathrm{~b}(60)$ & $205.2 \pm 23.54 \mathrm{~b}(54)$ & $321.1 \pm 11.09 \mathrm{a}(110)$ & $195.2 \pm 9.76 \mathrm{~b}(59)$ \\
\hline
\end{tabular}

P: period. Means in the same row followed by the same letter do not differ significantly at the $p<0.05$ level, as determined using the paired bootstrap test.

The age-stage-specific survival rate $\left(s_{x j}\right)$ is the probability that a newborn bean bug will survive to age $x$ and stage $j$ (Figure 1). The curves of each life stage show the survivorship, stage differentiation, and overlap among stages due to the variable rates of development among individuals. Adult females emerged at 32, 36, 31, and $33 \mathrm{~d}$ and survived until 136, 186,213 , and $196 \mathrm{~d}$ at $24.0^{\circ} \mathrm{C}, 24 \pm 4{ }^{\circ} \mathrm{C}, 24 \pm 6{ }^{\circ} \mathrm{C}$, and $24 \pm 8{ }^{\circ} \mathrm{C}$, respectively.

The age-specific survival rate and fecundity of $R$. pedestris are presented in Figures 2 and 3 , respectively. The age-specific survival rate $\left(l_{x}\right)$ is the sum of $s_{x j}$ at each age $x$ and is thus a simplified version of $s_{x j}$ shown in Figure 1. As shown in Figure 2, with exception of those individuals exposed to $24 \pm 6^{\circ} \mathrm{C}$, the curves decline sharply at a relatively early age. The fecundity curve, $m_{x}$, ended at ages $113,164,165$, and $160 \mathrm{~d}$ at $24.0^{\circ} \mathrm{C}, 24 \pm 4{ }^{\circ} \mathrm{C}, 24 \pm 6{ }^{\circ} \mathrm{C}$, and $24 \pm 8{ }^{\circ} \mathrm{C}$, respectively. The period from the first to the final reproduction under the four different temperature treatments ranged from $78 \mathrm{~d}\left(24.0^{\circ} \mathrm{C}\right)$ to $132 \mathrm{~d}\left(24 \pm 6{ }^{\circ} \mathrm{C}\right)$, whereas the highest age-specific fecundities were $4.11(45 \mathrm{~d}), 2.54(66 \mathrm{~d}), 3.86(46 \mathrm{~d})$, and 3.08 (47 d) eggs at $24.0^{\circ} \mathrm{C}, 24 \pm 4{ }^{\circ} \mathrm{C}, 24 \pm 6{ }^{\circ} \mathrm{C}$, and $24 \pm 8{ }^{\circ} \mathrm{C}$, respectively. 
Table 2. Population parameters and proportions of females, males, and N-type individuals of Riptortus pedestris under four different temperature conditions.

\begin{tabular}{|c|c|c|c|c|}
\hline \multirow{2}{*}{ Parameters } & \multicolumn{4}{|c|}{ Temperatures $\left({ }^{\circ} \mathrm{C}\right)$} \\
\hline & 24 & $24 \pm 4$ & $24 \pm 6$ & $24 \pm 8$ \\
\hline Pre-adult survival rate (\%) & $60.8 \pm 0.03 b(181)$ & $52.8 \pm 0.03 b(208)$ & $83.8 \pm 0.02 a(222)$ & $53.2 \pm 0.03 b(214)$ \\
\hline First age survival rate $<50 \%$ & $63.1 \pm 7.07 \mathrm{~b}(181)$ & $45.3 \pm 6.34 b(208)$ & $127.7 \pm 5.31 \mathrm{a}(222)$ & $52.4 \pm 13.75 b(214)$ \\
\hline Net reproductive rate $\left(R_{o}\right)$ & $73.4 \pm 9.37 \mathrm{~b}(181)$ & $53.2 \pm 8.67 \mathrm{~b}(208)$ & $159.1 \pm 12.07 \mathrm{a}(222)$ & $53.8 \pm 6.53 b(214)$ \\
\hline Intrinsic rate of increase $(r)$ & $0.08 \pm 0.002 b(181)$ & $0.05 \pm 0.002 \mathrm{~d}(208)$ & $0.09 \pm 0.001 \mathrm{a}(222)$ & $0.06 \pm 0.002 c(214)$ \\
\hline Finite rate of increase $(\lambda)$ & $1.08 \pm 0.002 b(181)$ & $1.05 \pm 0.002 \mathrm{~d}(208)$ & $1.09 \pm 0.001 \mathrm{a}(222)$ & $1.07 \pm 0.002 c(214)$ \\
\hline Mean generation time $(\mathrm{T})$ & $55.7 \pm 0.63 c(181)$ & $69.8 \pm 1.14 \mathrm{a}(208)$ & $59.1 \pm 0.43 b(222)$ & $57.2 \pm 0.91 b c(214)$ \\
\hline Proportion of female individuals $\left(\mathrm{N}_{f} / \mathrm{N}\right)$ & $33.2 \pm 0.03 b(181)$ & $26.0 \pm 0.03 b(208)$ & $49.6 \pm 0.03 a(222)$ & $27.6 \pm 0.03 b(214)$ \\
\hline Proportion of male individuals $\left(\mathrm{N}_{m} / \mathrm{N}\right)$ & $27.6 \pm 0.03 \mathrm{ab}(181)$ & $27.0 \pm 0.03 \mathrm{ab}(208)$ & $34.2 \pm 0.03 a(222)$ & $25.7 \pm 0.02 b(214)$ \\
\hline Proportion of N-type individuals $\left(\mathrm{N}_{n} / \mathrm{N}\right)$ & $39.2 \pm 0.03 a(181)$ & $47.1 \pm 0.03 a(208)$ & $16.2 \pm 0.03 b(222)$ & $46.7 \pm 0.03 a(214)$ \\
\hline
\end{tabular}

Means in the same row followed by the same letter do not differ significantly at the $(p<0.05)$ level, as determined by the paired bootstrap test. N-type means R. pedestris could not develop to adult stage. 


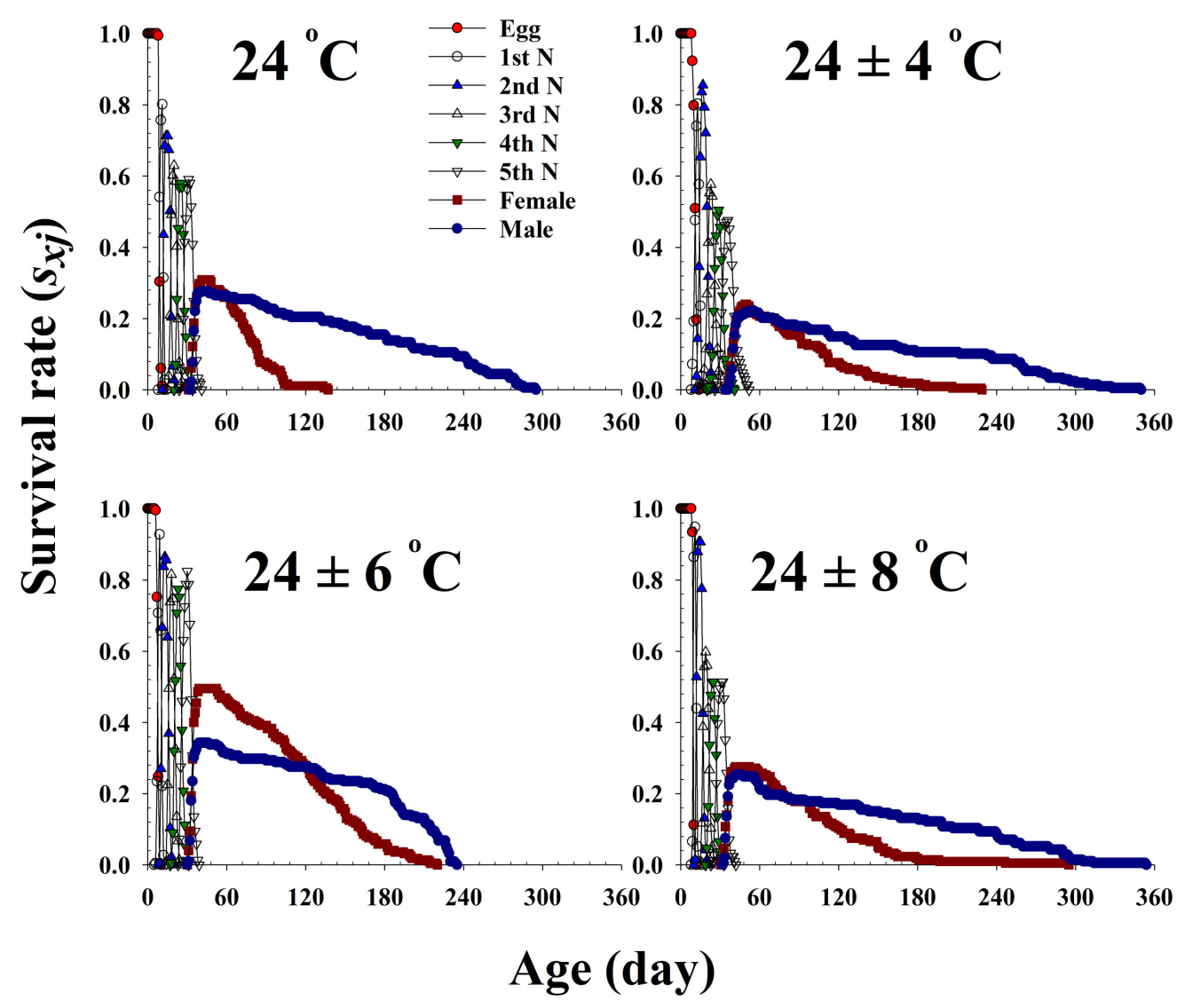

Figure 1. The age-stage-specific survival rate $\left(\mathrm{s}_{x j}\right)$ of Riptortus pedestris in response to different temperature conditions.

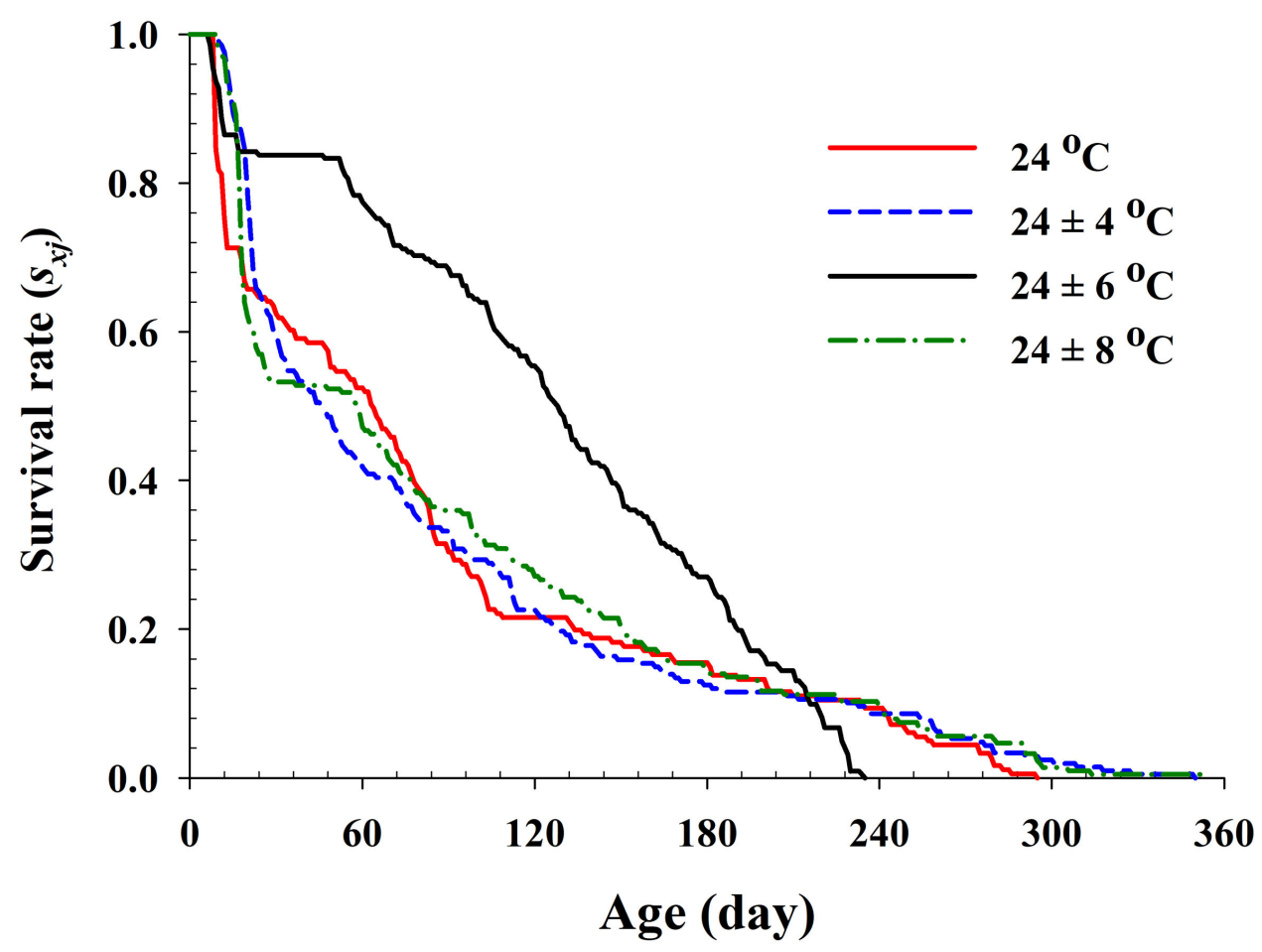

Figure 2. The age-specific survival rate $\left(l_{x}\right)$ of Riptortus pedestris in response to different temperature conditions. 


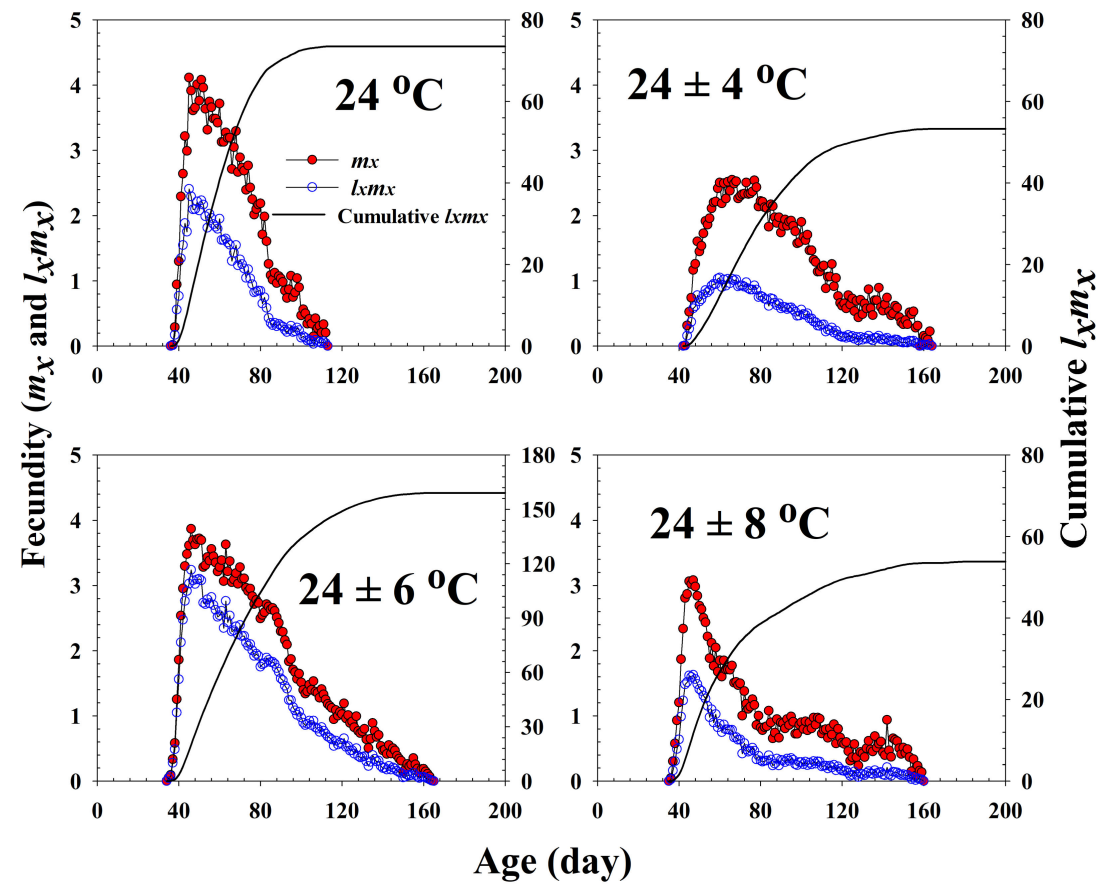

Figure 3. The age-specific fecundity $\left(m_{x}\right)$, the age-specific maternity $\left(l_{x} m_{x}\right)$, and the cumulative reproductive rate $\left(R_{x}=\sum l_{x} m_{x}\right)$ of Riptortus pedestris in response to different temperature conditions.

The life expectancy $\left(e_{x j}\right)$ of $R$. pedestris at different ages and stages under the four different temperature treatments is plotted in Figure 4. Each plot represents the expected survival of an individual at age $x$ and stage $j$. The curves for females and males show a decline with age. The life expectancy of females was $42.4,67.9,94.9$, and $82.1 \mathrm{~d}$ at $24.0^{\circ} \mathrm{C}$, $24 \pm 4{ }^{\circ} \mathrm{C}, 24 \pm 6{ }^{\circ} \mathrm{C}$, and $24 \pm 8{ }^{\circ} \mathrm{C}$, respectively.

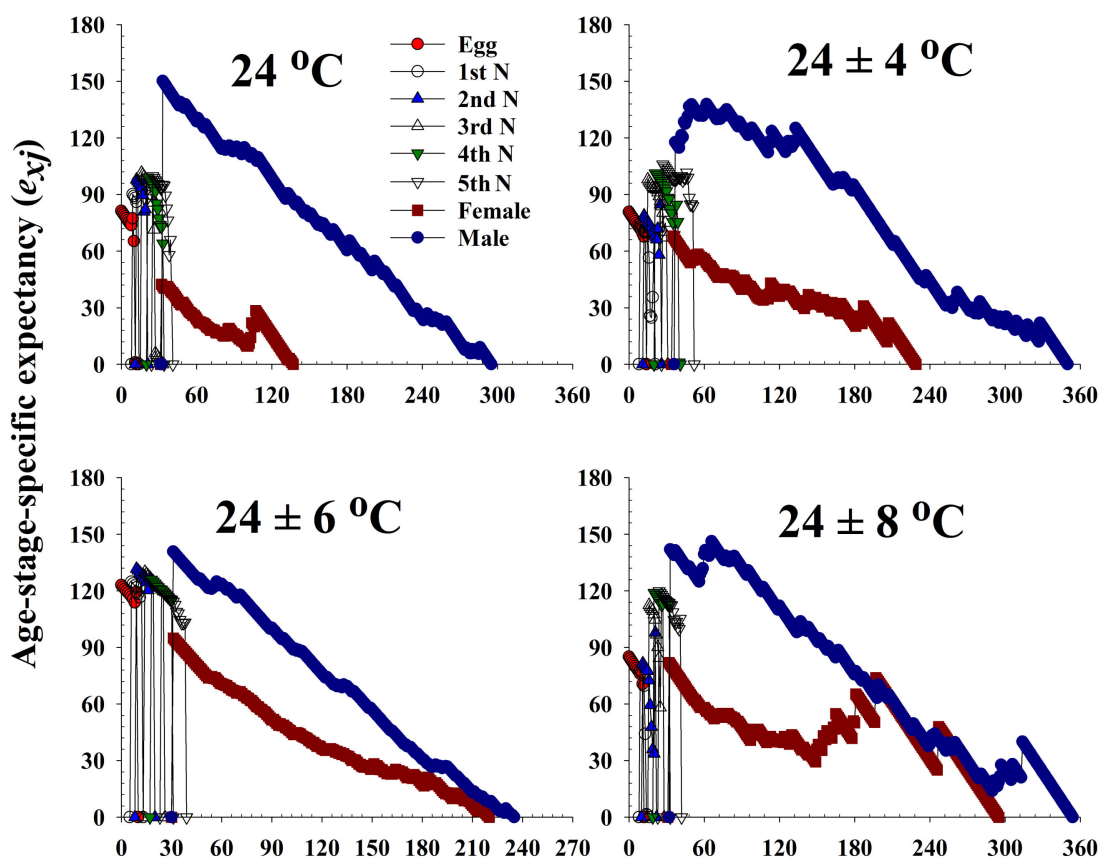

\section{Age (day)}

Figure 4. The age-stage life expectancy $\left(e_{x j}\right)$ of Riptortus pedestris in response to different temperature conditions. 
The age-stage-specific reproductive value $\left(v_{x j}\right)$ represents the contribution of an individual bean bug of age $x$ and stage $j$ to the future population (Figure 5). This value significantly increased with an increase in female emergence, and it peaked when females began to produce eggs. Major peaks in the reproductive values of the females maintained at $24.0^{\circ} \mathrm{C}, 24 \pm 4{ }^{\circ} \mathrm{C}, 24 \pm 6{ }^{\circ} \mathrm{C}$, and $24 \pm 8{ }^{\circ} \mathrm{C}$ were observed at 49 (80.03), 60 (71.60), 43 (67.69), and $42 \mathrm{~d}(61.58)$, respectively, and accordingly, the females at these ages contributed the most to the next generation.

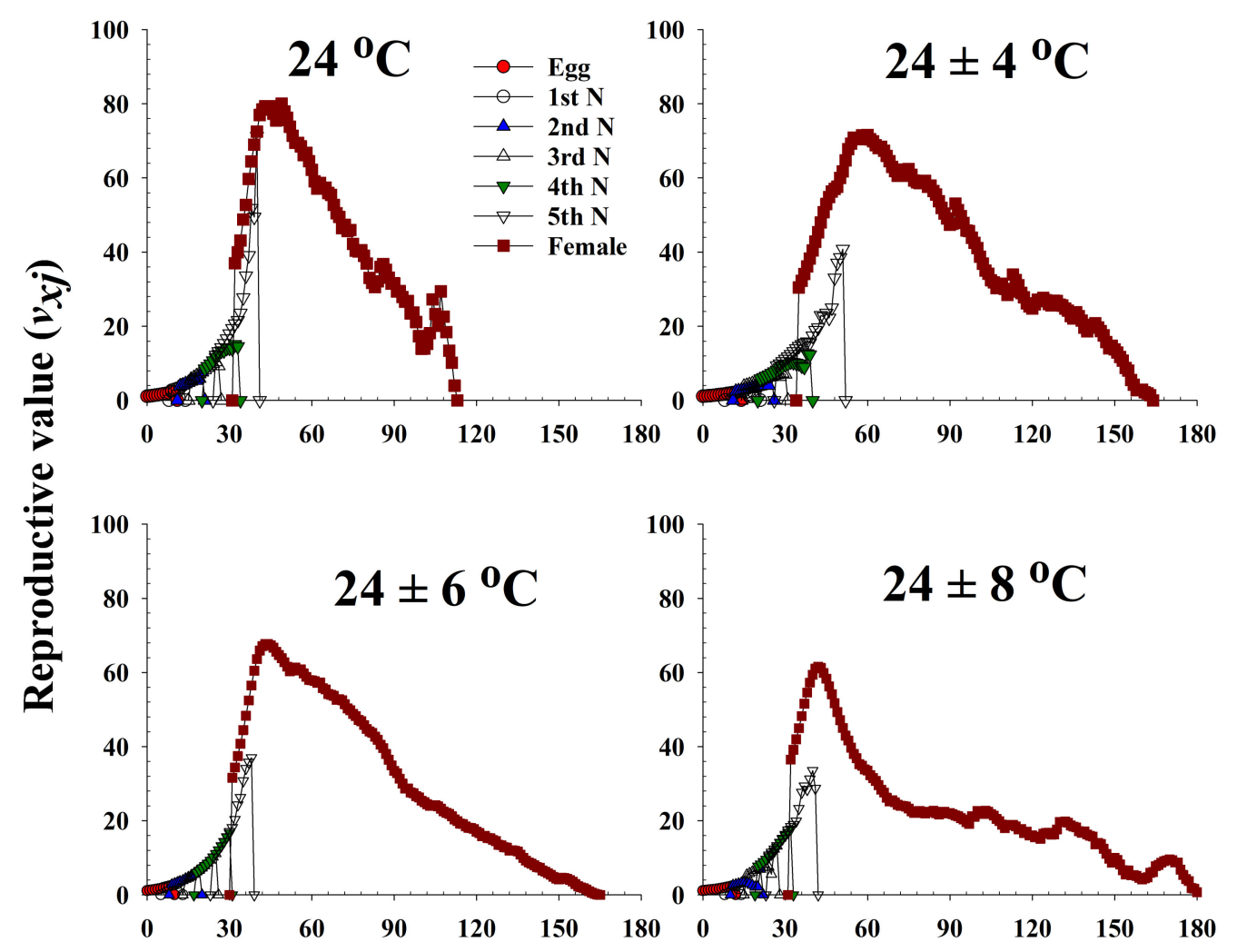

\section{Age (day)}

Figure 5. The age-stage-specific reproductive value $\left(v_{x j}\right)$ of Riptortus pedestris in response to different temperature conditions.

The derived population parameters assessed in this study are presented in Table 2 . The highest net reproductive rate $\left(R_{0} ; 159.1 \mathrm{offspring}\right)$ was observed at $24 \pm 6{ }^{\circ} \mathrm{C}$, whereas the lowest $R_{0}$ value (53.2 offspring) was obtained for females reared at $24 \pm 4{ }^{\circ} \mathrm{C}$. The highest intrinsic $\left(r=0.09 \mathrm{~d}^{-1}\right)$ and finite $\left(\lambda=1.09 \mathrm{~d}^{-1}\right)$ rates of increase for $R$. pedestris were recorded at $24 \pm 6{ }^{\circ} \mathrm{C}$, whereas the longest mean generation time ( $T=69.8 \mathrm{~d}$ ) was recorded at $24 \pm 4{ }^{\circ} \mathrm{C}$, which was 14 days longer than the $T$ value $(55.7 \mathrm{~d})$ at $24{ }^{\circ} \mathrm{C}$.

The population growth and stage structure at different temperature treatments based on age-stage, two-sex life table theory are shown in Figure 6. The populations subjected to the $24 \pm 6^{\circ} \mathrm{C}$ treatment were found to grow more rapidly than those exposed to the other three temperature conditions. The curves of the stage-specific growth rates of $R$. pedestris subjected to the different temperature treatments approached the intrinsic rate of increase for each temperature condition $\left(0.08,0.05,0.09\right.$, and 0.06 for $24.0{ }^{\circ} \mathrm{C}, 24 \pm 4{ }^{\circ} \mathrm{C}, 24 \pm 6{ }^{\circ} \mathrm{C}$, and $24 \pm 8{ }^{\circ} \mathrm{C}$, respectively; Table 2 and Figure 7 ). 


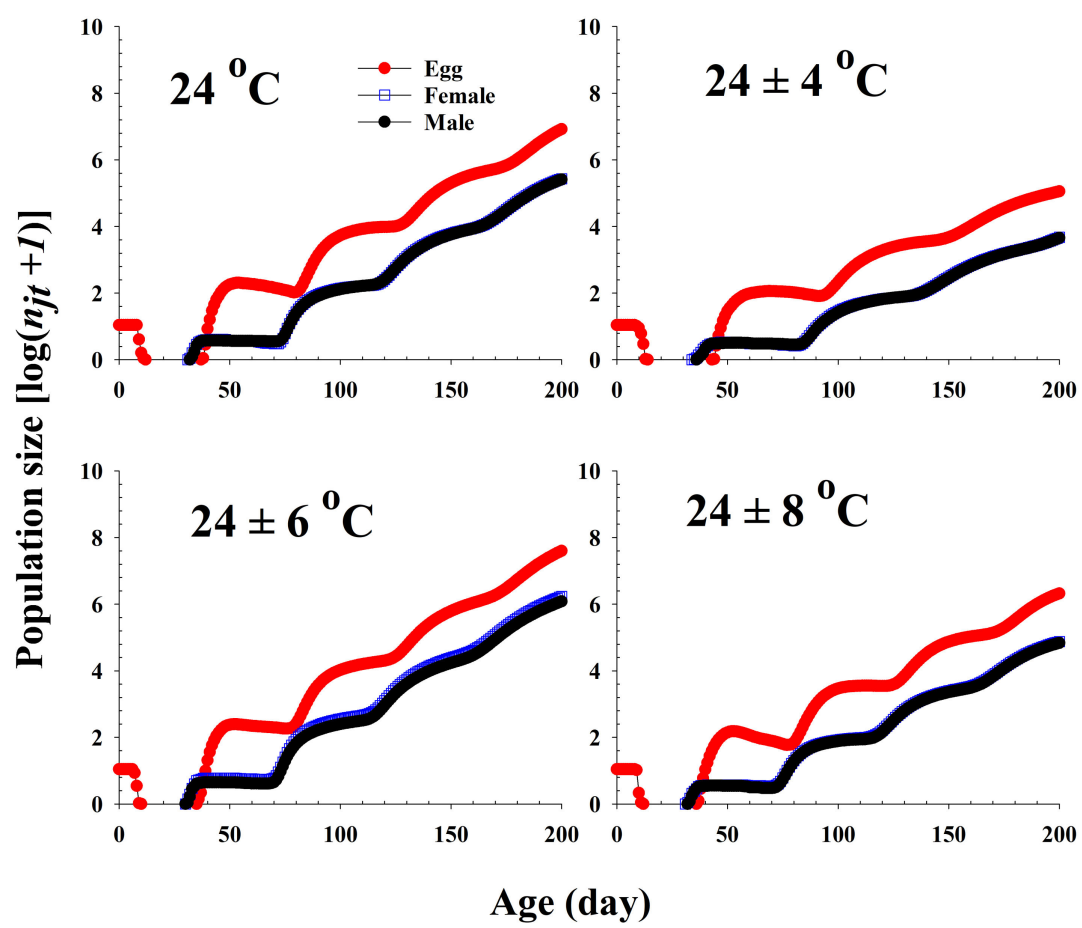

Figure 6. Projection of Riptortus pedestris population growth in response to different temperature conditions commencing with an initial population of newly laid 10 eggs.

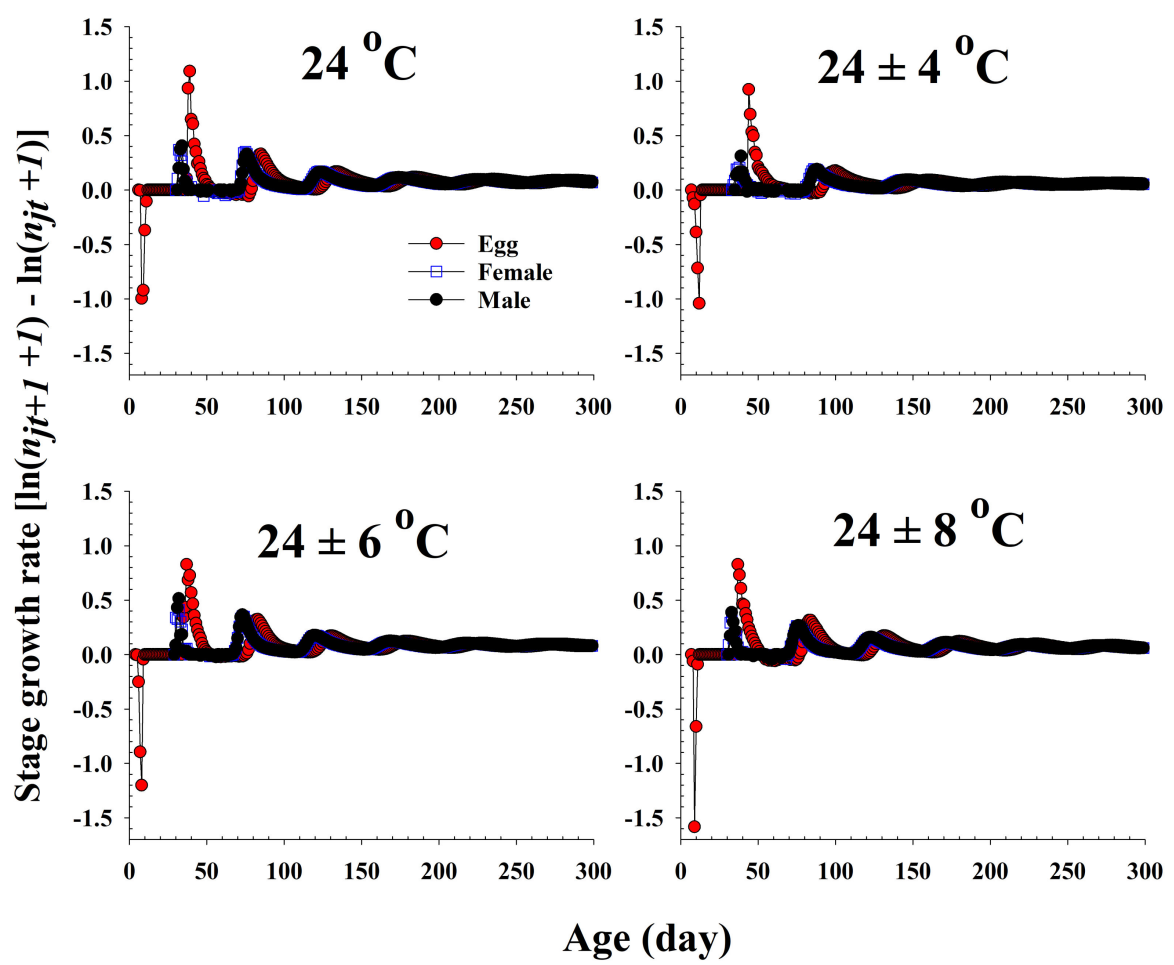

Figure 7. The stage growth rate of Riptortus pedestris in response to different temperature conditions.

\section{Discussion}

The primary objective of this study was to determine the impact of fluctuating temperatures on the development and reproduction of the bean bug $R$. pedestris. The effects of thermal conditions were assessed by constructing age-stage, two-sex life tables for sample populations exposed to a constant temperature of $24{ }^{\circ} \mathrm{C}$ and simulated fluctu- 
ating temperatures of $24 \pm 4{ }^{\circ} \mathrm{C}, 24 \pm 6{ }^{\circ} \mathrm{C}$, and $24 \pm 8{ }^{\circ} \mathrm{C}$. Our results showed that some life table parameters of $R$. pedestris were different from fluctuating temperature treatments compared to the constant temperature treatment. Compared to the constant temperature treatment, pre-adult development of $R$. pedestris was similar, but female longevity and oviposition period were significantly longer in fluctuating temperature treatments. These findings are partially consistent with the results of earlier studies on Bicyclus anynana [43], Helicoverpa armigera [44], Tetranychus urticae, Phytoseiulus persimilis, Neoseiulus californicus [45], and Megoura crassicauda and Aphis craccivora [46].

A number of studies have previously highlighted that experiments focusing primarily on the influence of average temperatures may not be sufficiently comprehensive to explain the variability of fluctuating temperature influences on insect thermal fitness [29-35,47-50]. Consequently, it is necessary to determine how fluctuations in temperature influence the thermal fitness of insects to gain insight into their biological responses when exposed to changing environments [49,51-53]. Cheng et al. [46] examined the impact of fluctuating temperatures on the development and reproduction of Megoura crassicauda and Aphis craccivora. They accordingly established that fluctuating temperatures accelerated the development of $M$. crassicauda and $A$. craccivora by significantly shortening the preadult period compared to the corresponding constant temperature. Furthermore, these authors found that fluctuating temperatures $\left(22 \pm 3{ }^{\circ} \mathrm{C}\right.$ and $22 \pm 5^{\circ} \mathrm{C}$ ) reduced the rate of adult $M$. crassicauda survival but increased that of $A$. craccivora [46]. Similarly, whereas reductions were observed in the oviposition period and fecundity of $M$. crassicauda under both fluctuating temperature treatments, increases were recorded for $A$. craccivora under the same conditions. Although no significant differences were detected between the species with respect to the population growth rate (intrinsic rate of increase) under the constant temperature, the simulated A. craccivora population grew significantly more rapidly than the $M$. crassicauda population when subjected to the two fluctuating temperature treatments [46]. Collectively, these findings indicated that fluctuating temperatures have detrimental effects on the life history traits of M. crassicauda, whereas the same conditions appear to be beneficial for A. craccivora. Another similar study by Bahar et al. [54] reported that the developmental times of the diamondback moth Plutella xylostella (Linnaeus) and its larval parasitoid Diadegma insulare (Cresson) were shortened under fluctuating temperatures $\left(0-14,15-29\right.$, and $\left.23-37{ }^{\circ} \mathrm{C}\right)$ compared with those under the corresponding constant temperatures of 7,22 , and $30{ }^{\circ} \mathrm{C}$, respectively. These findings may indicate that the effects of fluctuating temperatures on the population growth rate could be species-specific. Similarly, fluctuating temperatures appear to enhance the population growth rates of Spodoptera frugiperda [55], Helicoverpa armigera (Hübner) [44], Myzus persicae [47], and Tetranychus urticae Koch [45] and adversely affect Anagasta kuehniella [56]. Fluctuating temperatures may alter fitness components, including fecundity and longevity, dependent on insect sensitivity [11,57].

The intrinsic rate of increase includes contributions of age of initial reproduction, the peak of reproduction, length of the reproductive period, and the survival rate of the population. Population parameters are principal demographic parameters and are particularly useful when predicting the growth potential of insect populations [45,58-63]. Based on the intrinsic rate of increase values obtained in the present study, we established that fluctuating temperatures have different effects on $R$. pedestris development and reproduction, dependent on the ranges of temperature fluctuation to which these bugs were exposed. The higher values obtained in response to the $24 \pm 6{ }^{\circ} \mathrm{C}$ can plausibly be attributed to a shorter period of immature development and higher adult fecundity. Cheng et al. [46] reported that fluctuating temperatures had detrimental effects on the development and fertility of M. crassicauda, but they were beneficial for A. craccivora. Fluctuating temperatures have also been found to increase the population growth rates of H. armigera (Hübner) [44] and T. urticae Koch [45], whereas Rismayani et al. [64] observed a higher intrinsic rate of increase in Tetranychus pacificus under fluctuating temperatures around 10,20 , and $30^{\circ} \mathrm{C}$ than under the corresponding constant temperatures; the converse was true in the case of T. pacificus exposed to constant temperatures of 25 and $35^{\circ} \mathrm{C}$. 
Collectively, our findings indicate that the developmental periods, survival rates, longevity, reproductive capacities, and population growth of $R$. pedestris under fluctuating temperatures can often differ from those observed in response to a constant temperature. Fluctuating temperatures may create more resource-consuming environments than constant temperatures held at equivalent mean temperatures and tend to produce divergent responses. Given that temperature is one of the most important factors used in predicting population dynamics in nature, the effects of fluctuating temperatures should be carefully taken into account when attempting to forecast the population growth of $R$. pedestris.

\section{Conclusions}

In this study, we obtained fundamental information pertaining to the thermal development of all the life stages, life table parameters, and the population growth of $R$. pedestris reared under constant and fluctuating temperature conditions. The effects of thermal conditions were assessed by constructing age-stage, two-sex life tables for populations exposed to a constant temperature of $24{ }^{\circ} \mathrm{C}$ and simulated fluctuating temperatures of $24 \pm 4{ }^{\circ} \mathrm{C}$, $24 \pm 6^{\circ} \mathrm{C}$, and $24 \pm 8{ }^{\circ} \mathrm{C}$. We accordingly established that values obtained for a number of life table parameters of $R$. pedestris under constant temperature conditions differed from those obtained for populations exposed to fluctuating temperatures. Based on our findings, we believe that determining the population parameters and growth of $R$. pedestris under both constant and fluctuating temperature conditions would make a valuable contribution to predicting population fluctuations in field populations of $R$. pedestris and thus provide important information for implementing appropriate management practices. There are other factors such as photoperiod, diet, relative humidity, rearing density, sex, and all the interactions between these factors influencing on development rate in insects. Future studies may be needed to examine the biological performances of $R$. pedestris under different environmental conditions affecting insect development and fecundity.

Supplementary Materials: The following supporting information can be downloaded at: https:// www.mdpi.com/article/10.3390/insects13020113/s1, Figure S1: Stepwise process used in temperature cabinets for constant and fluctuating temperature regimes.

Author Contributions: Conceptualization, J.J.A.; Date Curation, J.J.A.; Formal Analysis, J.J.A.; Funding Acquisition, J.J.A.; Investigation, J.J.A.; Methodology, J.J.A.; Project Administration, J.J.A.; Resources, J.J.A.; Software, J.J.A. and K.S.C.; Supervision, J.J.A.; Validation, J.J.A.; Visualization, J.J.A.; Writing-Original Draft Preparation, J.J.A.; Writing-Review \& Editing, J.J.A. and K.S.C. All authors have read and agreed to the published version of the manuscript.

Funding: This research was supported by the research program of National Institute of Horticultural and Herbal Science (PJ01206002), Rural Development Administration.

Institutional Review Board Statement: Not applicable.

Data Availability Statement: Data presented in this study are available in the article.

Acknowledgments: The authors thank for Kwon Soo Kang and Gun Hee Kwon for their enthusiastic help.

Conflicts of Interest: The authors declare no conflict of interest. The funders had no role in the design of the study; in the collection, analyses, or interpretation of data; in the writing of the manuscript, or in the decision to publish the results.

\section{References}

1. Visalakshi, A.; Jacob, A.; Nair, M.R.G.K. Biology of Riptortus pedestris F. (Coreidae: Hemiptera), a pest of cow-pea. Entomon 1976, 1, 139-142.

2. Kono, S. Analysis of soybean seed injuries caused by three species of stink bugs. Jpn. J. Appl. Entomol. Zool. 1989, 33, 128-133. [CrossRef]

3. Leal, W.S.; Higuchi, H.; Mizutani, N.; Nakamori, H.; Kadosawa, T.; Ono, M. Multifunctional communication in Riptortus clavatus (Heteroptera: Alydidae): Conspecific nymphs and egg parasitoid Ooencyrtus nezarae use the same adult attractant pheromone as chemical cue. J. Chem. Ecol. 1995, 21, 973-985. [CrossRef] [PubMed]

4. Lim, U.T. Occurrence and Control Method of Riptortus pedestris (Hemiptera: Alydidae): Korean Perspectives. Korean J. Appl. Entomol. 2013, 52, 437-448. [CrossRef] 
5. Li, K.; Zhang, X.; Guo, J.; Penn, H.; Wu, T.; Li, L.; Jiang, H.; Chang, L.; Wu, C.; Han, T. Feeding of Riptortus pedestris on soybean plants, the primary cause of soybean staygreen syndrome in the Huang-Huai-Hai river basin. Crop J. 2019, 7, 360-367. [CrossRef]

6. Harris, R.M.B.; Beaumont, L.J.; Vance, T.R.; Tozer, C.R.; Remenyi, T.; Perkins-Kirkpatrick, S.E.; Mitchell, P.J.; Nicotra, A.B.; McGregor, S.; Andrew, N.R.; et al. Biological responses to the press and pulse of climate trends and extreme events. Nat. Clim. Chang. 2018, 8, 579-587. [CrossRef]

7. Jactel, H.; Koricheva, J.; Castagneyrol, B. Responses of forest insect pests to climate change: Not so simple. Curr. Opin. Insect Sci. 2019, 35, 103-108. [CrossRef]

8. Lehmann, P.; Ammunét, T.; Barton, M.; Battisti, A.; Eigenbrode, S.D.; Jepsen, J.U.; Kalinkat, G.; Neuvonen, S.; Niemelä, P.; Terblanche, J.S.; et al. Complex responses of global insect pests to climate warming. Front. Ecol. Environ. 2020, 18, 141-150. [CrossRef]

9. Aguila, L.C.R.; Hussain, M.; Huang, W.; Lei, L.; Bamisile, B.S.; Wang, F.; Chi, H.; Wang, L. Temperature-dependent demography and population projection of Tamarixia radiata (Hymenoptera: Eulophidea) reared on Diaphorina citri (Hemiptera: Liviidae). J. Econ. Entomol. 2019, 113, 55-63.

10. Ahn, J.J.; Choi, K.S.; Koh, S. Effects of temperature on the development, fecundity, and life table parameters of Riptortus pedestris (Hemiptera: Alydidae). Appl. Entomol. Zool. 2019, 54, 63-74. [CrossRef]

11. Colinet, H.; Sinclair, B.J.; Vernon, P.; Renault, D. Insects in Fluctuating Thermal Environments. Annu. Rev. Entomol. 2015, 60, 123-140. [CrossRef]

12. Cui, J.; Zhu, S.-Y.; Bi, R.; Xu, W.; Gao, Y.; Shi, S.-S. Effect of temperature on the development, survival, and fecundity of Heliothis viriplaca (Lepidoptera: Noctuidae). J. Econ. Entomol. 2018, 111, 1940-1946. [CrossRef]

13. Govindan, B.N.; Hutchinson, W.D. Influence of temperature on age-stage, two-sex life tables for a Minnesota-acclimated population of the brown marmorated stink bug (Halyomorpha halys). Insects 2020, 11, 108. [CrossRef]

14. Nelson, W.A.; Bjørnstad, O.N.; Yamanaka, T. Recurrent Insect Outbreaks Caused by Temperature-Driven Changes in System Stability. Science 2013, 341, 796-799. [CrossRef]

15. Nooten, S.S.; Andrew, N.R.; Hughes, L. Potential Impacts of Climate Change on Insect Communities: A Transplant Experiment. PLOS ONE 2014, 9, e85987. [CrossRef]

16. Ruel, J.J.; Ayres, M.P. Jensen's inequality predicts effects of environmental variation. Trends Ecol. Evol. 1999, 14, 361-366. [CrossRef]

17. Wu, T.-H.; Shiao, S.-F.; Okuyama, T. Development of insects under fluctuating temperature: A review and case study. J. Appl. Entomol. 2015, 139, 592-599. [CrossRef]

18. Chi, H.; Su, H.-Y. Age-stage, two-sex life tables of Aphidius gifuensis (Ashmead) (Hymenoptera: Braconidae) and its host Myzus persicae (Sulzer) (Homoptera: Aphididae) with mathematical proof of the relationship between female fecundity and the net reproductive rate. Environ. Entomol. 2006, 35, 10-21. [CrossRef]

19. Huang, Y.-B.; Chi, H. Age-stage, two-sex life tables of Bactrocera cucurbitae (Coquillett) (Diptera: Tephritidae) with a discussion on the problem of applying female age-specific life tables to insect populations. Insect Sci. 2012, 19, 263-273. [CrossRef]

20. Akca, I.; Ayvaz, T.; Yazici, E.; Smith, C.L.; Chi, H. Demography and population projection of Aphis fabae (Hemiptera: Aphididae) With additional comments on life table research criteria. J. Econ. Entomol. 2015, 108, 1466-1478. [CrossRef]

21. Chen, G.-M.; Chi, H.; Wang, R.-C.; Wang, Y.-P.; Xu, Y.-Y.; Li, X.-D.; Yin, P.; Zheng, F.-Q. Demography and uncertainty of population growth of Conogethes punctiferalis (Lepidoptera: Crambidae) reared on five host plants with discussion on some life history statistics. J. Econ. Entomol. 2018, 111, 2143-2152. [CrossRef]

22. Huang, K.Y.-B.; Atlihan, R.; Gökçe, A.; Huang, J.Y.-B.; Chi, H. Demographic Analysis of Sex Ratio on Population Growth of Bactrocera dorsalis (Diptera: Tephritidae) With Discussion of Control Efficacy Using Male Annihilation. J. Econ. Entomol. 2016, 109, 2249-2258. [CrossRef]

23. Shi, M.-Z.; Li, J.-Y.; Ding, B.; Fu, J.-W.; Zheng, L.-Z.; Chi, H. Indirect effect of elevated CO2 on population parameters and growth of Agasicles hygrophila (Coleoptera: Chrysomelidae), a biological agent of alligatorweed (Amaranthaceae). J. Econ. Entomol. 2019, 112, 1120-1129. [CrossRef]

24. Tang, Q.; Ma, K.; Chi, H.; Hou, Y.; Gao, X. Transgenerational hermetic effects of sublethal dose of flupyradi-furone on the green peach aphid, Myzus persicae (Sulzer) (Hemiptera: Aphididae). PLoS ONE 2019, 14, e0208058. [CrossRef] [PubMed]

25. Chi, H.; You, M.; Atlihan, R.; Smith, C.L.; Kavousi, A.; Özgökçe, M.S.; Güncan, A.; Tuan, S.-J.; Fu, J.-W.; Xu, Y.-Y.; et al. Age-stage, two-sex life table: An introduction to theory, data analysis, and application. Entomol. Gen. 2020, 40, 103-124. [CrossRef]

26. Kim, H.; Baek, S.; Kim, S.; Lee, S.-Y.; Lee, J.-H. Temperature-dependent development and oviposition models of Riptortus clavatus (Thunberg) (Hemiptera: Alydidae). Appl. Entomol. Zool. 2009, 44, 515-523. [CrossRef]

27. Rahman, M.M.; Lim, U.T. Evaluation of mature soybean pods as a food source for two pod-sucking bugs, Riptortus pedestris (Hemiptera: Alydidae) and Halyomorpha halys (Hemiptera: Pentatomidae). PLoS ONE 2017, 12, e0176187. [CrossRef]

28. Maia, A.H.N.; Luiz, A.J.B.; Campanhola, C. Statistical inference on associated fertility life table parameters using jackknife technique: Computational aspects. J. Econ. Entomol. 2000, 93, 511-518. [CrossRef]

29. Cloudsley-Thompson, J.L. The significance of fluctuating temperatures on the physiology and ecology of insects. Entomologist 1953, 86, 183-189.

30. Economos, A.C.; Lints, F.A. Developmental temperature and life span in Drosophila melanogaster. II. Oscillating temperature. Gerontology 1986, 32, 28-36. [CrossRef] [PubMed] 
31. Fischer, K.; Kölzow, N.; Höltje, H.; Karl, I. Assay conditions in laboratory experiments: Is the use of constant rather than fluctuating temperatures justified when investigating temperature induced plasticity? Oecologia 2011, 166, 23-33. [CrossRef]

32. Kingsolver, J.G.; Ragland, G.J.; Diamond, S.E. Evolution in a constant environment: Thermal fluctuations and thermal sensitivity of laboratory and field populations of Manduca sexta. Evolution 2009, 63, 537-541. [CrossRef]

33. Kjarsgaard, A.; Pertoldi, C.; Loeschcke, V.; Blanckenhorn, W.U. The effect of fluctuating temperatures during development on fitness-related traits of Scatophaga stercoraria (Diptera: Scathophagidae). Environ. Entomol. 2013, 42, 1069-1078. [CrossRef]

34. McCalla, K.A.; Keçeci, M.; Milosavijević, I.; Ratkowsky, D.A.; Hoddle, M.A. The influence of temperature variation on life history parameters and thermal performance curves of Tamarixia radiata (Hymenoptera: Eulophidae), a parasitoid of the Asian citrus psyllid (Hemiptera: Liviidae). J. Econ. Entomol. 2019, 112, 1560-1574. [CrossRef]

35. Milosavijević, I.; McCalla, K.A.; Ratkowsky, D.A.; Hoddle, M.A. Effects of constant and fluctuating temperatures on development rates and longevity of Diaphorencyrtus aligarhensis (Hymenoptera: Encyrtidae). J. Econ. Entomol. 2019, 112, 1062-1072. [CrossRef]

36. Chi, H.; Liu, H. Two new methods for the study of insect population ecology. Bull. Inst. Zool. Acad. Sin. 1985, 24, 225-240.

37. Chi, H. Life-Table Analysis Incorporating Both Sexes and Variable Development Rates Among Individuals. Environ. Entomol. 1988, 17, 26-34. [CrossRef]

38. Chi, H. TWOSEX-MSChart: A Computer Program for the Age-Stage, Two-Sex Life Table Analysis 2020. Available online: http:/ /140.120.197.173/Ecology/Download/Twosex-MSChart.exe-B100000.rar (accessed on 20 January 2020).

39. Goodman, D. Optimal Life Histories, Optimal Notation, and the Value of Reproductive Value. Am. Nat. 1982, 119, 803-823. [CrossRef]

40. Tuan, S.J.; Lee, C.C.; Chi, H. Population and damage projection of Spodoptera litura (F.) on peanuts (Arachis hypogaea L.) under different conditions using the age-stage, two-sex life table. Pest. Manage. Sci. 2014, 70, 805-813. [CrossRef]

41. Efron, B.; Tibshirani, R.J. An Introduction to the Bootstrap; Chapman \& Hall: New York, NY, USA, 1993.

42. Chi, H. TIMING-MSChart: A Computer Program for the Population Projection Based on Age-Stage, Two-Sex Life Table 2020. Available online: http:/ /140.120.197.173/Ecology/Download/Timing-MSChart.rar (accessed on 20 January 2020).

43. Brakefield, P.M.; Mazzotta, V. Matching field and laboratory environments: Effects of neglecting daily temperature variation on insect reaction norms. J. Evol. Biol. 1995, 8, 559-573. [CrossRef]

44. Mironidis, G.K.; Savopoulou-Soultani, M. Development, survivorship, and reproduction of Helicoverpa armigera (Lepidoptera: Noctuidae) under constant and alternating temperatures. Environ. Entomol. 2008, 37, 16-28. [CrossRef] [PubMed]

45. Vangansbeke, D.; De Schrijver, L.; Spranghers, T.; Audenaert, J.; Verhoeven, R.; Nguyen, D.T.; Gobin, B.; Tirry, L.; De Clercq, P. Alternating temperatures affect life table parameters of Phytoseiulus persimilis, Neoseiulus californicus (Acari: Phytoseiidae) and their prey Tetranychus urticae (Acari: Tetranychidae). Exp. Appl. Acarol. 2013, 61, 285-298. [CrossRef]

46. Cheng, L.-Y.; Chang, Y.; Chen, Z.-Z.; Xu, Y.-Y. Effects of constant and fluctuating temperatures on development and reproduction of Megoura crassicauda and Aphis craccivora (Hemiptera: Aphididae). Entomol. Fenn. 2018, 29, 1-12. [CrossRef]

47. Bannerman, J.A.; Gillespie, D.R.; Roitberg, B.D. The impacts of extreme and fluctuating temperatures on trait-mediated indirect aphid-parasitoid interactions. Ecol. Entomol. 2011, 36, 490-498. [CrossRef]

48. Kingsolver, J.G.; Buckley, L.B. Quantifying thermal extremes and biological variation to predict evolutionary responses to changing climate. Philos. T. Roy. Soc. B. 2017, 372, 20160147. [CrossRef]

49. Vasseur, D.A.; DeLong, J.P.; Gilbert, B.; Greig, H.S.; Harley, C.D.G.; McCann, K.S.; Savage, V.; Tunney, T.D.; O'Connor, M.I. Increased temperature variation poses a greater risk to species than climate warming. P. Roy. Soc. B Biol. Sci. 2014, 281, 20132612. [CrossRef]

50. Williams, C.M.; Buckley, L.B.; Sheldon, K.S.; Vickers, M.; Pörtner, H.-O.; Dowd, W.W.; Gunderson, A.R.; Marshall, K.E.; Stillman, J.H. Biological Impacts of Thermal Extremes: Mechanisms and Costs of Functional Responses Matter. Integr. Comp. Biol. 2016, 56, 73-84. [CrossRef] [PubMed]

51. Chidawanyika, F.; Mudavanhu, P.; Nyamukondiwa, C. Global Climate Change as a Driver of Bottom-Up and Top-Down Factors in Agricultural Landscapes and the Fate of Host-Parasitoid Interactions. Front. Ecol. Evol. 2019, 7, 80. [CrossRef]

52. Mutamiswa, R.; Machekano, H.; Chidawanyika, F.; Nyamukondiwa, C. Life-stage related responses to combined effects of acclimation temperature and humidity on the thermal tolerance of Chilo partellus (Swinhoe) (Lepidoptera: Crambidae). J. Therm. Biol. 2019, 79, 85-94. [CrossRef]

53. Stephens, A.E.A.; Kriticos, D.J.; Leriche, A. The current and future potential geographical distribution of the oriental fruit fly, Bactrocera dorsalis (Diptera: Tephritidae). Bull. Entomol. Res. 2007, 97, 369-378. [CrossRef]

54. Bahar, M.H.; Soroka, J.J.; Dosdall, L.M. Constant versus fluctuating temperatures in the interactions between Plutella xylostella (Lepidoptera: Plutellidae) and its larval parasitoid Diadegma insulare (Hymenoptera: Ich-neumonidae). Environ. Entomol. 2012, 41, 1653-1661. [CrossRef] [PubMed]

55. Simmons, A.M. Effects of Constant and Fluctuating Temperatures and Humidities on the Survival of Spodoptera frugiperda Pupae (Lepidoptera: Noctuidae). Fla. Entomol. 1993, 76, 333. [CrossRef]

56. Siddiqui, W.H.; Barlow, C.A. Population Growth of Anagasta kuehniella (Lepidoptera: Pyralidae) at Constant and Alternating Temperatures. Ann. Entomol. Soc. Am. 1972, 66, 579-585. [CrossRef]

57. Hagstrum, D.W.; Leach, C.E. Role of Constant and Fluctuating Temperatures in Determining Development Time and Fecundity of Three Species of Stored-Products Coleoptera. Ann. Entomol. Soc. Am. 1973, 66, 407-410. [CrossRef]

58. Birch, L.C. The Intrinsic Rate of Natural Increase of an Insect Population. J. Anim. Ecol. 1948, 17, 15. [CrossRef] 
59. Ahn, J.J.; Choi, K.S.; Koh, S. Population parameters and growth of Riptortus pedestris (Fabricius) (Hemiptera: Alydidae) under elevated $\mathrm{CO}_{2}$ concentrations. Entomol. Res. 2021, 51, 12-23. [CrossRef]

60. Ahn, J.J.; Cho, J.R.; Kim, J.-W.; Seo, B.Y. Thermal effects on the population parameters and growth of Acrythosi-phon pisum (Harris) (Hemiptera: Aphididae). Insects 2020, 11, 481. [CrossRef]

61. Seo, B.Y.; Kim, E.Y.; Ahn, J.J.; Kim, Y.; Kang, S.; Jung, J.K. Development, Reproduction, and Life Table Parameters of the Foxglove Aphid, Aulacorthum solani Kaltenbach (Hemiptera: Aphididae), on Soybean at Constant Temperatures. Insects 2020, 11, 296. [CrossRef]

62. Ali, M.Y.; Naseem, T.; Arshad, M.; Ashraf, I.; Rizwan, M.; Tahir, M.; Rizwan, M.; Sayed, S.; Ullah, M.I.; Khan, R.R.; et al. Host-plant variation affect the biotic potential, survival, and population projection of Myzus persicae (Hemiptera: Aphididae). Insects 2021, 12, 375. [CrossRef]

63. Wang, T.; Ren, Y.-L.; Tian, T.-A.; Li, Z.-T.; Wang, X.-N.; Wu, Z.-Y.; Tang, J.; Liu, J.-F. Determining the Effect of Temperature on the Growth and Reproduction of Lasioderma serricorne Using Two-Sex Life Table Analysis. Insects 2021, 12, 1103. [CrossRef]

64. Rismayani, R.; Ullah, M.S.; Chi, H.; Gotoh, T. Impact of Constant and Fluctuating Temperatures on Population Characteristics of Tetranychus pacificus (Acari: Tetranychidae). J. Econ. Entomol. 2021, 114, 638-651. [CrossRef] 